Europe's Journal of Psychology 4/2009, pp. 71-103

www.ejop.org

\title{
Depressive Symptoms and Their Correlates with Locus of Control and Satisfaction with Life among Jordanian College Students
}

\author{
Jehad Alaedein Zawawi, Ph.D \\ Assistant Professor of Counseling Psychology, Department of Educational \\ Psychology, Hashemite University - Jordan
}

Shaher H. Hamaideh, Ph.D.

Assistant Professor of Community \& Mental Health Nursing, Department of PsychiatricMental Health Nursing, Hashemite University- Jordan

\begin{abstract}
Objective: to establish estimates of the prevalence of depressive symptoms, and their correlates with locus of control and satisfaction with life among undergraduate students in Hashemite University (HU) - Jordan. Method: A randomized sample of college students ( $N=492), 67$ (33.9\%) were male, completed the Multidimensional Health Locus of Control Scale (MHLC), the Satisfaction with Life Scale (SLS), and the Center for Epidemiologic Studies Depression Scale (CES-D). Results: Study outcomes showed a great ratio of depressive symptoms among HU students, almost half of college-aged individuals had a major depression, and statistical analyses showed no relationship between externality of locus of control (Powerful others) and depression, while Externality of locus of control (Chance) was found to be significantly positively related to depression, and in line to previous studies a significant negative relationship was found between internality of locus of control and depression. Additionally, significant negative relationship was found between satisfaction with life (SLS) and depression. However, Satisfaction with life was found to be the first best predictor of depressive symptoms and Chance was found to be the second best predictor of depressive symptoms. Conclusion: Findings of this study hold implications for depressive symptoms interventions, such as expanding psychoeducation courses to include strategies for enhancing and maintaining a sense of personal control and selfactualization.
\end{abstract}

Keywords - External Locus of Control; Internal Locus of Control; Satisfaction with Life; Depressive Symptoms; College Students. 
Introduction

Most lifetime mental health disorders have first onset during or shortly before the typical college age (Kessler, et al., 2005), and these problems may be precipitated or exacerbated by the variety of stressors in college life, including separation from family, sharing close living quarters with strangers, the formation of new social groups, intense academic pressures and the balancing of social engagements with academic and other life responsibilities (Marano, 2002). While all of these circumstances offer opportunities for growth, they may also result in stress that precipitates the onset or recurrence of psychiatric or mental health disorders (Blanco et al., 2008).

Although most of those young people manage to handle college life stresses and challenges with aplomb, others have difficulty adjusting. They are experiencing emotional turmoil, suffering from depressed mood, believing their lives are controlled by outside forces rather than their own efforts, and feeling discontented with life. In response, some seek out artificial and unhealthy means of improving their mood or numbing their unpleasant thoughts and feelings (National Center on Addiction and Substance Abuse [NCASA], Columbia University, 2003). Increases in external locus of control among college students may be related to the concurrent trends toward increased depression and anxiety, drug abuse, and diminished academic achievement (Twenge, Zhang \& Im, 2004).

Accordingly, this study provides information regarding the relationship between depression and some personality cognitive factors (locus of control and satisfaction with life) in college students. College may be a key time for catching and treating depression, specifically, mental health problems among college students related to depression should not be a hindrance to their education and development. Successful intervention by college counseling centers may prevent future episodes of depression over the lifetime as well as improve the college experience for students suffering from depressed mood, and distortion in cognition.

In Jordan, depression may be highly prevalent among young adults. According to statistics released by the Jordanian Ministry of Health, the number of depressed patients in the Ministry's psychiatric clinics rose last year to reach $(23,369)$ cases, of them $(11,622)$ males, and $(11,747)$ females, mostly or about $(19,000)$ cases in the age group of $(15-45)$ years (Dellewany, 2006). One 
national study suggested a prevalence of depression of greater than $30 \%$ in 493 randomly selected female patients treated at primary health care out-patient centers in West Amman, Jordan (Hamid et al., 2004). Al-Khulaidi (2004) found in her study that $18.1 \%$ of the college students' sample $(n=703)$, suffer from severe depression. A recent study conducted by Jordanian psychiatrist Dr. Jamal alKhatib, concluded that $40 \%$ of the cases of private psychiatric clinics are university students, $23 \%$ of high school students, and $8 \%$ of community college graduates (as cited by Dellewany, 2006).

Similarly, at international level, depression is widespread in college campuses. For example, a recent study (Blanco et al., 2008) found (45.8) percent of American college students $(n=2,188)$, age 19 to 25 , met the criteria for at least one psychiatric disorder. Almost half of college-aged individuals meet criteria for depression, personality disorders or another mental health condition, but only one-fourth of those seek treatment. Also, results of a survey by the American College Health Association (Kisch, Leino, \& Silverman, 2005) found that $62.2 \%$ of students had experienced feelings of hopelessness at least once during the past year, and $44.4 \%$ reported having experienced being "so depressed it was difficult to function" (p. 7), and In Furr, Westefeld, McConnell and Jenkins' study (2001) of 1,455 college student participants, up to 53 percent reported having experienced depression since beginning college.

Accordingly, many studies explored the cognitive factors that have been implicated in depression, and support the notion that an internal health locus of control orientation is negatively correlated with depression (Afifi, Al Riyami, Morsi \& Al Kharusil, 2006; Benassi, Sweeney \& Dufour, 1988; Twenge et al., 2004) and positively correlated with life satisfaction (Klonowicz, 2001; Rapaport, Clary, Fayyad, \& Endicott, 2005; Simpson, Schumaker, Dorahy, \& Shrestha, 1996; Sunders \& Roy, 2000).

Despite this plethora in depression and its correlates' research, there is a paucity of research examining issues of depression for Arab college students in general, and much less for Jordanian college students in particular.

This research advances knowledge of student mental health and seeks to explore some personality variables, specifically cognitive factors that predict depression occurrence among college students. In particular, studies showed that locus of control and satisfaction with life represent alarm indicators to depression in early intervention prevention programs. 


\section{Depressive Symptoms}

In the present study, the operational definition of depression refers to the depressive symptoms in accordance to the score on the Center for Epidemiologic Studies Depression Scale (CES-D) (Radloff, 1977).

Depressive symptoms describe emotional experiences ranging from occasional periods of sadness to very serious disorders or chronic loss of interest or pleasure in nearly all activities.

According to Beck's (1967) cognitive theory on depression, cognitive distortions in depressed individuals lead them to view themselves, their environment, and their future in a negative manner, which has a significant impact on the onset and the continuation of the disorder (Haley, Fine, Marriage, Moretti, \& Freeman, 1985; McCauley, Mitchell, Burke, \& Moss, 1988). Beck (1967) has found evidence that "deviation from logical and realistic thinking was found at every level of depression from mild neurotic to severe psychotic" (p. 240). From a somehow different perspective, Abramson and his colleagues $(1989,1978)$ have proposed a model of depression that is related to learned helplessness and state that individuals can come to perceive outcomes as uncontrollable because of their lack of success and inevitable lack of control. When individuals see themselves as helpless, as a consequence of thinking that outcomes are not related to their efforts, they will attribute a reason for their helplessness. For instance, if an individual makes an internal attribution to his or her helplessness, and therefore sees his or her powerlessness as a personal shortcoming, this can lead to an increase in passivity and a loss in self-esteem and motivation. Consequently, this causes impairments in the individual's emotions and cognition, which create a sufficient condition for depressed mood. This attribution style of internalizing helplessness has been found in depressed adults, as well as among children and adolescents with depressive symptoms (McCauley et al., 1988).

Many researches on depression, with behavioral and cognitive perspectives, have focused on the relationship between individuals' control beliefs and depression and claimed that there is an association between depression and locus of control (Nolen-Hoeksema, Larson, \& Grayson, 1999; Weisz, Sweeney, \& Carr, 1993). Someone with external locus of control believes that outside factors, such as chance, fate or luck, determine the outcome of events, whereas internal locus of control is explained as an individual's perception that 
his or her own actions and efforts have an effect on the outcome of events (Chubb, \& Fertman, 1997).

In relation to this, a frequent topic of investigation is whether internal locus of control or external locus of control is associated with depression. It appears that the most dominating support has been given to the view that states that more external locus of control is correlated with more depression (Benassi et al., 1988). For example, McCauley and his colleagues (1988) demonstrated in a study on depression in children and adolescents that the depressed group had lower scores on self-concept and higher scores on external locus of control, compared to the control groups. Greater internality in an individual, in contrast, has been found to be connected with successful adjustment in school, independency, responsible behavior, and more self-control. However, locus of control should be viewed as a continuous variable, which implies that an individual's locus of control may change between different situations (Chubb, \& Fertman, 1997).

Furthermore, psychosocial aspects, such as parental emotional detachment, conflicts in the family and weak family cohesion are related to children's depression (Petersen et al., 1993). However, factors that influence depression cannot be established separately, instead they are in a complex interaction and related to an individual's characteristics and biospsychosocial context (Pelkonen, Marttunen, \& Aro, 2003; Petersen et al., 1993). Murphy \& Wetzel (1990) assert that comorbidity of depression and alcohol abuse is common, "Major depression was one and one half times more frequent in alcoholics than non-alcoholics" (p. 390). Individuals who are developing a drinking problem may be ingesting alcohol to relieve feelings of boredom, depression, anxiety, or inadequacy (Rotter, 1966). Alcohol abuse is not the only cause of depression in college students. Other major factors associated with depression among college students are grade problems, money problems, and relationship problems (Furr et al., 2001).

\section{Locus of Control}

Locus of control is viewed as "a cognitive expectancy which defined the individual's view of causal factors related to these outcomes" (Nunn, 1995, p. 421). Rotter (1966) defined locus of control as a "generalized expectancy of internal versus external control over behavior outcomes". Although this trait is no doubt distributed normally among people, those who believe that they are 
influenced by external forces are considered to have an external locus of control. However, those who have confidence that whatever happens to them, pleasant or unpleasant, is substantially within their domain of influence are said to have a predominantly internal locus of control (Tones, 1997).

Levenson developed an alternative model in 1973. Whereas Rotter's concept viewed locus of control as unidimensional (internal to external), Levenson's model asserts that there are three independent dimensions: Internality, Chance, and Powerful Others. According to Levenson's model, one can endorse each of these dimensions of locus of control independently and at the same time. For example, a person might simultaneously believe that both oneself and Powerful Others influence outcomes, but that Chance does not.

Different models were developed in order to identify factors that affect changes over time in locus of control. Several authors connected externality to conformity and internality to individual action (Crowne \& Liverant, 1963; Kelman \& Lawrence, 1972). In contrast, the alienation model (see Twenge et al., 2004) asserts that locus of control has become more external today due to greater individuation. This model focuses on two historical trends: the tendency to blame one's misfortunes on outside forces, and increases in negative social indicators. It reflects the greater cynicism, distrust, and alienation of recent generations (Fukuyama, 1999; Pharr, Putnam \& Dalton, 2000; Sloan, 1996).

Since its introduction, the locus of control construct has undergone considerable elaboration, and several context-specific instruments have been developed. Health researchers in particular have embraced locus of control as a concept for explaining behavior. Among the most widely used health-specific measures is the multidimensional health locus of control scale (Wallston, Wallston, \& DeVellis, 1978). This instrument retains Levenson's three dimensions but is focused on outcomes that are specifically related to health and illness, such as staying well or becoming ill.

For this study, locus of control is operationally defined by the Multidimensional Health Locus of Control scales (MHLC scales Form A; Wallston et al., 1978).

Life Satisfaction

Many of the studies that focus on what makes people content with their lives distinguish between two related aspects: the cognitive and affective dimensions of subjective well-being (SWB). The cognitive dimension is usually 
referred to as life satisfaction, whereas the affective dimension represents positive and negative emotions such as happiness and loneliness (Klonowicz, 2001).

Most researchers agree that, although life satisfaction fluctuates over time (Diener, Oishi, \& Lucas, 2003), in the long run, even exhilarating or traumatic events do not change it drastically. One explanation for that is that personality explains most of the variability in life satisfaction, and, as personality traits and dispositions tend to be stable over time, they create stability in levels of life satisfaction (Spector et al., 2001). Researchers refer to diverse aspects of personality when discussing life satisfaction. Some focus on locus of control (e.g., Spector et al., 2001; Wardle et al., 2004) others on depression (e.g., Hong, \& Giannakopoulos, 1994).

Life Satisfaction in this study refers to the extent to which individuals are satisfied with the progress of their own life, as measured by the Satisfaction with Life Scale (Diener, Emmons, Larsen, \& Griffin, 1985; Pavot, Diener, Colvin, \& Sandvik, 1991).

\section{Literature}

To examine the relationship between locus of control and depression, Banks and Goggin (1983) conducted a study with a sample of college students $(\mathrm{N}=100)$ who completed Rotter's (1966) Internal-External Locus of Control Scale, The Attributional Style Scale, and Beck Depression Inventory. Statistical analyses showed no relationship between externality of locus of control and depression, and a significant interaction existed between attribution and locus of control, leading to the conclusions that individuals who are either internal or external on both locus of control and attribution are least depressed, while individuals who are internal on one and external on the other are the most depressed. The authors (1983) concluded that both external locus of control (i.e., a generalized expectancy that reinforcement is controlled by luck or fate instead of oneself) and internal locus of attribution (i.e., beliefs that success or failure result from an individual's actions rather than external causes) have been related to depression.

Burger (1984) found that locus of control scores, particularly the extent to which college students perceived that their lives were controlled by chance, were significantly related to the depression levels. It was also found that high desire 
for control subjects who held external perceptions of control were most likely to seek nonprofessional help for depression. In addition, high desire for control subjects who perceived their lives as generally controlled by chance were most likely to have suicidal thoughts. Brown and Siegel (1988) also found a link between perceived control and depressive affect. In their study, 176 female adolescents were studied at two times approximately eight months apart. Participants were administered a measure of life stress, an attribution questionnaire, and the Center for Epidemiologic Studies Depression Scale (CESD). Via hierarchical regression analyses, they found that internal, stable, and global attributions for negative events attributed to uncontrollable causes were related to increases in depressive affect. Conversely, internal and global attributions for negative events attributed to controllable causes were related to less depressive affect. Benassi and his colleagues (1988) in their meta-analysis study, found strong support for the hypothesis that greater externality is associated with greater depression. In their major analysis, they obtained a mean effect size of .31. The analyses based on Levenson's (1973) dimensions of internality, powerful others, and chance produced mean effect sizes of .23, .38, and .31 , respectively.

Klonowicz (2001) studied the relationship between locus of control and life satisfaction in a population of individuals with reactive temperaments. The data suggested that high reactivity coupled with external locus of control was more often associated with lower ratings of subjective well-being. Further analysis indicated that life satisfaction was most influenced by locus of control rather than by reactivity, thus suggesting the relative strength of locus of control beliefs. Twenge and her colleagues (2004) in their meta-analysis study for (97) samples of college students ( $n=18,310$ ), conclude that college students in 2002 had a more external locus of control than $80 \%$ of college students in the early 1960s, and found that externality is correlated with poor school achievement, helplessness, and depression. Weitzman (2004) study describes patterns of poor mental health/depression (PMHD) in a national sample of college students and the relationships among PMHD, alcohol consumption, harm, and abuse. Responses to mailed questionnaires completed by a random sample of 27,409 students at 119 colleges were analyzed using logistic regression. $4.8 \%$ of students reported PMHD. The average college prevalence was $5.01 \%$ (range, $0.68 \%$ to $13.23 \%)$. Students with PMHD were more likely than their peers to be female and from low socioeconomic status families, less likely to report never drinking. Rapaport and his colleagues (2005) investigated quality of life among individuals with a variety of anxiety and depressive disorders who were enrolled in a clinical psychopharmacology trial. Participants completed the Quality of 
Life Enjoyment and Satisfaction Questionnaire, which assesses global quality of life as well as quality of life in a variety of domains including physical health; social and family relations; functional ability; and participation in work, hobbies, leisure, and household activities. Substantial proportions of participants with chronic depression (85\%), major depressive disorder (63\%), and PTSD (59\%) reported severely impaired quality of life, and impairment occurred across domains.

Afifi and his colleagues (2006) explored the rate and correlates of depressive symptoms among 5409 secondary school adolescents in Oman. High score in negative health locus of control, low score in positive health locus of control, poor relationship with family members, friends and teachers significantly predicted depressive symptoms in the logistic regression model. Having a hobby and never dropping a class were protective variables. Finally, Afifi (2007) investigated the association of health locus of control with depression among adolescents in Alexandria, Egypt. The tools used were the Multidimensional Health Locus of Control scale and the Child Depression Inventory. Adolescents with low internal health locus of control and high chance external health locus of control were more likely to have depressive symptoms than others. The study findings demonstrated an association between health locus of control and adolescent depression.

Building on past research, the present study was designed to examine the relationship between self-reported depressive symptoms and cognitive style in college students. It was hypothesized that perception of internal locus of control (i.e., the belief that the individual personally has control over life events and environment), perception of external locus of control (i.e., the belief that chance, and powerful others determine fate), and unsatisfactory with life would be negatively and positively, respectively, related to depressive symptoms significantly.

Significance of the Study

College is a critical context for studying youth mental health. Although young adulthood is often characterized by rapid intellectual and social development, college-aged individuals are also commonly exposed to circumstances that place them at risk for mental health and psychiatric disorders. Mental health disorders appear to be common among 18 - to 24-year-olds, college students (Blanco et al., 2008). 
Uncovering the personality cognitive factors correlates with these mental health disorders, such as depression, will help counselors to work actively and put forth directly deliberate programs to deal with this serious area. This study is significant because it contains therapeutic implications. Identifying predictors of depression may help participants enhance their quality of life, avert rapid decline, and live longer. This study may have implications for counseling services and enhance adjustment among university students. A main implication is to improve existing services or design new services to have more control and personal responsibility in an environment where they usually feel out of control. Another implication is that this study is generating new knowledge with focus on psychological cognitive variables and specifically locus of control and satisfaction with life can contribute to the body of young adulthood research, since predicting depression and avoiding psychological morbidity contributes to the well-being and quality of life of college students. Information in enhancing personal control and life satisfaction, in the lives of those young adults, may assist the mental and physical health professional to create tools for assisting those adolescents and youth who are struggling with lack of control over their lives, and may call universities' attention to the mental health needs of young adults, according to background information in the study.

\section{Research Questions}

The purpose of this study is to explore and answer the following research questions:

1. What is the prevalence rate of depressive symptoms among college students at Hashemite University [HU]?

2. What are the relationships among locus of control, satisfaction with life, and depressive symptoms, among college students at HU?

3. Are there significant differences in depressive symptoms, locus of control, and satisfaction with life, among university students in relation to their academic achievement, substance abuse, financial problems, and perception of health?

4. What are the best predictors for depressive symptoms among HU students?

Method

Sampling and Data Collection

Target population of the current study was all students at $\mathrm{HU}$ who registered in the first semester courses for the academic year 2008-2009, which 
approximately equals to 18,000 students. (For the purpose of this study, we did not include graduate students). Stratified random sampling according to academic level (year) was used to select participants for this study.

After getting the approval from the Scientific Research Committee at HU, to conduct the study, the registration department office at the HU provided the researchers with a list of all courses offered to all undergraduate students during the first semester of the academic year (2008-2009) according to the course level (first, second, third, and fourth). Numbers were assigned to each course, then two courses from each group were selected using simple random sampling. Then, the researchers contacted the teacher/instructor of each selected course to set a plan for data collection during the class lectures. There were 610 students in the randomly selected courses, 492 (response rate=80.6\%) were agreed to participate in the study and responded to a questionnaire for extra credit. The average age of the students was 20.32 years (SD=1.55). The questionnaire consisted of the three measures given below.

\section{Procedures and Research Design}

Each participant completed a packet of questionnaires with demographic information included during one of several scheduled testing times. Participants were not asked to include their names or any identifying information. The following measures were administered: (a) The MHLC, (b) the SLS (c) the CES-D. Average time to complete all 43 items was approximately 15 minutes. Each participant was given extra credit point for completing the measures, providing the applicant's course grade with five extra points. All participants were treated in accordance with the American Psychological Association's ethical principles.

Measures

Three instruments Multidimensional Health Locus of Control Scale form A, Satisfaction with Life Scale, and Center for Epidemiologic Studies Depression Scale, in addition to the demographic sheet, were used to collect the data in this study. For the purpose of this study, by using the 'forward-backward' procedure, the English version of the three instruments was translated into the Arabic language by an expert in bilingual language, then another bilingual expert translated the Arabic version into English without accessing to the original version. A third bilingual faculty member compared the translated Arabic and the translated English versions, corrected any incongruence in the translation. No significant variation between the two was detected. These 
instruments have been translated into many languages, and for many of these translations validation studies confirm the internationally applicable nature of these tools. Also, these scales are in the public domain. Therefore, they may be used without copyright permission.

1. Multidimensional Health Locus of Control Scale MHLC-form A, (Waltson et al.,1978), was used to assess locus of control. This scale has been used in many educational and psychological researches and cited frequently in the literature (Afifi, 2007). This scale consists of 18 items each of which is rated on a 6-point Likert-type scale ranging from 1 (strongly disagree) to 6 (strongly agree). This scale contains three 6-item subscales: Internality (beliefs in internal or personal control over health), Powerful Others (such as medical staff, family and friends), Chance (external locus of control or beliefs in chance and fate) (Norman, \& Bennett, 1996). Ratings were summed for each scale. Therefore, scores for each subscales ranged from 6 to 36. Items include "If I take care of myself, I can avoid illness"; "When I get sick, I am to blame". Higher scores indicate greater beliefs in internal, powerful others, and chance control over health. In the current study, Cronbach's alpha for (MHLC), Form A was 0.63 and Guttman split-half alpha was 0.53, with moderate internal consistency: Cronbach's alpha values for the subscales were 0.67 (Internality), 0.56 (Powerful Others), and 0.66 (Chance). In addition, average three-week test-retest reliability coefficient for MHLC subscales was $0.68,0.60$, and 0.65 , respectively.

2. Satisfaction with Life Scale (SLS) was used to assess life satisfaction (Diener, Emmons, Larsen, \& Griffin, 1985). This scale which is used to assess the level of satisfaction with life, consists of 5 items scored on a 7-point Likert scale ranging from 1 (strongly disagree) to 7 (strongly agree). A total score is calculated by summing the individual responses to the 5 items. Scores on the total scale ranged from 5 to 35. Items include "In most ways my life is close to my ideal ". The higher the score, the more satisfied the individual with his/her life. The Satisfaction with Life Scale (SLS) was developed to assess satisfaction with the respondent's life as a whole. The scale does not assess satisfaction with life domains such as health or finances but allows subjects to integrate and weight these domains in whatever way they choose. In the current study, Cronbach's alpha for SLS was 0.79, and Guttman split-half alpha was 0.77. In addition, average three-week test-retest reliability coefficient for SLS was 0.78.

3. Center for Epidemiologic Studies Depression Scale (CES-D) (Radloff, 1977). The CES-D is a valuable tool for identifying a group at-risk for depression and for studying the relationship between depressive symptoms and other variables, 
was used in the current study to assess level of depressive symptoms. CES-D is a 20-item self-report scale designed to measure multiple dimensions of affective symptomatology and current depressive symptoms within the last week in the general population. The scale addresses six components of depression: depressed mood, feelings of guilt and worthlessness, feelings of helplessness and hopelessness, psychomotor function, loss of appetite, and sleep disturbances. The scale also can distinguish between clinical groups and general community groups. The scale addresses four factors: depressed affect (7 items), somatic symptoms (6 items), reversed positive affect, (4 items), and interpersonal difficulties (3 items). Each item is rated on 4-point Likert-type scale indicating the degree of their occurrence during the last week. The items' responses range from 0 (rarely or none of the time) to 3 (most all of the time). Items include: "I felt sad," "I felt that I was just as good as other people," and "I felt I could not get going. A total score is ranged from 0 to 60 . A score of 22 or higher indicates probable Major Depression. A score between 15 and 21 indicates the need for more in-depth assessment and treatment for Mild to Moderate Depression. A score of 14 or less is not indicative of depression. The total CES-D scores reflect a sum of reversed positive affect, negative affect, somatic symptoms, and interpersonal relations. Overall, the total CES-D scores and scale scores for each subcategory were examined in the present study. Although it is usually scored continuously, there are various cut-off scores for clinical depression with reasonable associations between cut-off scores and clinical diagnosis. A widely used cut-off to identify depressed individuals is a score of 16 or greater on the CES-D. Acceptable validity and reliability have been found across a wide variety of demographic characteristics [76]; [78]. In the current study, Cronbach's alpha for CES-D was 0.86 and Guttman split-half alpha was 0.87; with high internal consistency: Cronbach's alpha values for the subscales were 0.85 (depressed affect), 0.89 (somatic symptoms) and 0.84 (reversed positive affect), and 0.86 (interpersonal difficulties). Average threeweek test-retest reliability coefficient for CES-D total scores was 0.88 .

4. Academic Achievement refers in the selected sample to student grade point average (GPA) with scores ranging from 4-0, as follows: excellent (3.5-4.0); very good (3.0-3.49); good (2.5-2.99); acceptable (2.0-2.49); weak (below 2.0). Values were classified in three n-tiles, one central n-tile. (P25 to P75), and two ntiles than $50 \%$ of the grade point average level, were used to compare results.

5. Substance Abuse refers to students' usage of various substances. A single question was given to the participants to determine whether usage of various substances $(\mathrm{No}=1)$ or $(\mathrm{Yes}=2)$. 
6. Financial Difficulties refer to student's experience of a financial problem while managing his college expenses. A single question was given to the participants to determine this experience $(\mathrm{No}=1)$ or $(\mathrm{Yes}=2)$.

7. Perception of Health refers to self-rated overall students' health. A single question given to the participants concerning their self-rated overall health was used with a scale ranging from one to five; poor 1; average 2; good 3; very good 4; or excellent 5. Values were classified in three n-tiles, one central n-tile. (P25 to P75), and two n-tiles than $50 \%$ of the Perception of Health level, were used to compare results.

\section{Data Analysis}

Data were analyzed using Statistical Package for Social Sciences (SPSS version 12.0, 2006). Descriptive statistics were used to generate means, standard deviations, and frequencies for a list of variables. In addition, research questions were answered by employing correlations, ANOVA, and step-wise multiple regression.

\section{Results}

1. Description of demographics: The sample consisted of 492 undergraduate students. Age of the participants ranged between 17-29 years ( $M=20.32, S D=$ 1.55). There were 167 male (33.9\%) of the sample. Only 55 (11.2\%) of the participants' mothers are currently employed outside home. Sixty-nine (14.0\%) of the participants are working in different areas beside their role as students. Only $86(17.5 \%)$ of the participants were regular smokers, and 48 participants (9.8\%) who abused substance or more during the last month. Of the total sample, 214 participants $(43.5 \%)$ indicated that they suffer from financial problems, and only 71 (14.4\%) students participated usually in extracurricular activities at the university (See Table 1).

Table 1. Sample's Demographic Variables ( $N=492)$.

\begin{tabular}{ll}
\hline Variable & $N(\%)$ \\
Students' Level (Year) & $152(30.9)$ \\
First year & $98(19.9)$ \\
Second year & $96(19.5)$ \\
Third year & $146(29.7)$ \\
Fourth year & $265(53.8)$ \\
$\begin{array}{l}\text { Students' Faculty } \\
\text { Humanistic }\end{array}$ &
\end{tabular}




\begin{tabular}{ll}
\hline Scientific & $227(46.2)$ \\
Grade Point Average (GPA) & $39(8.1)$ \\
Excellent (3.5-4.0) & $146(30.3)$ \\
Very Good (3.0-3.49) & $184(38.2)$ \\
Good (2.5-2.99) & $97(20.1)$ \\
Acceptable (2.0-2.49) & $16(3.3)$ \\
Weak (below 2.0) & \\
Substance Abuse & $27(5.5)$ \\
Alcohol & $16(3.3)$ \\
Calming drugs & $3(0.6)$ \\
Stimulant drugs & $2(0.4)$ \\
Hashish & $48(9.7)$ \\
Yes & $444(90.2)$ \\
No & $214(43.5)$ \\
Financial Difficulties & $278(56.5)$ \\
Yes & \\
No & \\
Students' self-perception of & $128(26.0)$ \\
health & $238(48.4)$ \\
Excellent & $110(22.4)$ \\
Very Good & $11(2.2)$ \\
Good & $5(1.0)$ \\
Average & \\
Poor &
\end{tabular}

2. The first research question is targeting the prevalence rate of depressive symptoms among students at HU. Results of the total scores in CES-D (TOT depressive symptoms) showed that 47.8 percent and 24.4 percent of students suffered from major depression and mild-moderate depression, respectively. While the rest (27.8 percent), have no indicative of depression (See Table 2).

\section{Table 2}

TOT Depressive symptoms scores of study sample $(\mathrm{N}=492)$ on the three levels of Depression*

\begin{tabular}{|c|c|c|c|c|c|c|}
\hline & \multicolumn{4}{|c|}{ Three Levels of Depression* } \\
\hline & & & 1 & 2 & 3 & Total \\
\hline \multirow{2}{*}{$\begin{array}{l}\text { TOT } \\
\text { Depressive } \\
\text { symptoms }\end{array}$} & Total & Count & 137 & 120 & 235 & 492 \\
\hline & & $\begin{array}{l}\text { \% within } \\
\text { Depressive } \\
\text { symptoms }\end{array}$ & $27.8 \%$ & $24.4 \%$ & $47.8 \%$ & $100.0 \%$ \\
\hline
\end{tabular}

$* 1=0-14$ (Not indicative of depression); 2=15-21 (Mild-moderate depression);

$3=22$ and higher (Major depression).

3. We had three $(2,3$, and 4) additional basic research questions, each of which is presented separately below. The second question was strictly 
correlational in nature: Are both cognitive (locus of control and life satisfaction) constructs related to student Depressive Symptoms. The results are reflected in Table 3. Virtually most of the variables are related significantly to the other variables at the .0 .01 level. All but 2 correlations were significant at the .0 .05 level (rs > .107; .095).

These results indicate, first, that sufficient systematic variability exists for relations to emerge if they exist, and, second, that cognitive constructs are related to student depressive symptoms. In fact, the variation in sizes of correlations indicates that different aspects of cognitive styles correspond differentially with different aspects of student depressive symptoms. This idea is examined in more detail below (see Table3).

Table3. Intercorrelations between Measures of cognitive constructs (locus of control and life satisfaction) related to student Depressive Symptoms ( $\mathrm{N}=492)$

\begin{tabular}{|c|c|c|c|c|c|c|c|c|c|}
\hline & & 1 & 2 & 3 & 4 & 5 & 6 & 7 & 8 \\
\hline 1 & $\frac{\text { Locus of Control }}{\text { Internality }}$ & 1.0 & & & & & & & \\
\hline 2 & $\begin{array}{r}\text { Externality: Powerful } \\
\text { others }\end{array}$ & $0.362^{* *}$ & 1.0 & & & & & & \\
\hline 3 & Externality: Chance & 0.074 & $0.154^{* *}$ & 1.0 & & & & & \\
\hline 4 & Satisfaction with life & $0.150^{* *}$ & $.131^{* *}$ & $-.135^{* *}$ & 1.0 & & & & \\
\hline 5 & $\frac{\text { Depressive Symptoms }}{\text { Depressive affect }}$ & -0.047 & -0.027 & $0.169^{* *}$ & $.449^{* *}$ & 1.0 & & & \\
\hline 6 & Somatic & -0.073 & -0.008 & $0.142^{* *}$ & $-.300 * *$ & $0.642^{* *}$ & 1.0 & & \\
\hline 7 & Reversed positive affect & ${ }^{-}-19^{* *}$ & -0.063 & $0.140^{* *}$ & $-.393^{* *}$ & $0.563^{* *}$ & $0.427^{* *}$ & 1.0 & \\
\hline 8 & Interpersonal difficulties & $-0.107^{*}$ & -0.073 & $0.165^{* *}$ & $-.370^{* *}$ & $0.519^{* *}$ & $0.440^{* *}$ & $0.329 * *$ & 1.0 \\
\hline 9 & $\begin{array}{r}\text { TOT Depressive } \\
\text { Symptoms }\end{array}$ & $-.095^{*}$ & -.037 & $.190^{* *}$ & $-.472^{* *}$ & $.914^{* *}$ & $.827^{* *}$ & $.731^{* *}$ & $\begin{array}{c}616^{*} \\
*\end{array}$ \\
\hline
\end{tabular}

${ }^{*} p<.0 .05 .{ }^{* *} p<.0 .01$. two-tailed

Internality $(M=23.54 ; S D=5.39)$, Powerful others $(M=21.12 ; S D=5.87)$, Chance (Externality)

$(M=18.24 ; S D=4.83)$, Satisfaction with life $(M=19.79 ; S D=6.63)$, Depressive

$\operatorname{affect}(M=7.01 ; S D=5.17)$, Somatic( $M=7.97 ; S D=4.03)$, Reversed positive affect

$(M=6.37 ; S D=3.07)$, Interpersonal difficulties $(M=1.23 ; S D=1.61)$, TOT depressive

symptoms $(M=22.60 ; S D=11.30)$.

4. The third question addressed whether there are significant differences in locus of control, satisfaction with life, and depressive symptoms, among students in relation to their academic achievement, substance abuse, financial problems, and perception of health. Univariate analysis of variance (ANOVA) between independent variables (Selected Demographic Variables) and dependent variables (Locus of Control, Satisfaction with Life, and Depressive Symptoms) was conducted. The results are reflected in Table 4. 
Table 4. Univariate analysis of variance (ANOVA) between independent variables (Selected Demographic Variables) and dependent variables (Locus of Control, Satisfaction with Life, and Depressive Symptoms) ( $N=492)$.

\begin{tabular}{|c|c|c|c|c|}
\hline & $\begin{array}{c}\text { Academic } \\
\text { Achievement }\end{array}$ & $\begin{array}{l}\text { Substance } \\
\text { Abuse }\end{array}$ & $\begin{array}{l}\text { Financial } \\
\text { Difficulties }\end{array}$ & $\begin{array}{c}\text { Perception of } \\
\text { Health }\end{array}$ \\
\hline Locus of control & F (Sig.) & F (Sig.) & F (Sig.) & F (Sig.) \\
\hline $\begin{array}{l}\text { Internality } \\
\text { (Externality) }\end{array}$ & $\begin{array}{l}0.154(.695) \\
2.250(.134)\end{array}$ & $\begin{array}{l}0.148(.701) \\
0.325(.553)\end{array}$ & $\begin{array}{l}4.498\left(.034^{*}\right) \\
0.475(.491)\end{array}$ & $\begin{array}{l}0.826(.364) \\
1.627(.203)\end{array}$ \\
\hline $\begin{array}{l}\text { Powerful others } \\
\text { (Externality) } \\
\text { Chance }\end{array}$ & 0.000 (.987) & $0.442(.506)$ & $15.024\left(.000^{* *}\right)$ & 2.442 (.1 19) \\
\hline $\begin{array}{l}\text { Satisfaction with } \\
\frac{\text { life }}{\text { Depressive }}\end{array}$ & $\begin{array}{c}10.182 \\
\left(.002^{* *}\right)\end{array}$ & $4.104\left(.043^{*}\right)$ & $73.340\left(.000^{* *}\right)$ & $12.243\left(.001^{* *}\right)$ \\
\hline$\frac{\text { Symptoms }}{\text { Depressive affect }}$ & $2.499(.115)$ & $3.566(.060)$ & $18.133\left(.000^{* *}\right)$ & $9.191\left(.003^{* *}\right)$ \\
\hline Somatic & $1.207(.273)$ & $9.227\left(.003^{* *}\right)$ & $13.612(.000 * *)$ & $11.726\left(.001^{* *}\right)$ \\
\hline $\begin{array}{l}\text { Reversed positive } \\
\text { affect }\end{array}$ & $3.443(.064)$ & $0.884(.348)$ & $20.119\left(.000^{* *}\right)$ & $10.622\left(.001^{* *}\right)$ \\
\hline $\begin{array}{l}\text { Interpersonal } \\
\text { difficulties }\end{array}$ & $0.257(.613)$ & $0.000(.948)$ & $17.052\left(.000^{* *}\right)$ & $1.031(.310)$ \\
\hline $\begin{array}{l}\text { TOT Depressive } \\
\text { symptoms }\end{array}$ & $2.290(.059)$ & $4.834\left(0.28^{*}\right)$ & $26.200\left(.000^{* *}\right)$ & $10.390\left(.000^{* *}\right)$ \\
\hline
\end{tabular}

These results indicate that there was a statistically significant effect for first, Academic Achievement $(f(1,490)=10.18$ (.002), $p<.01)$ in the satisfaction with life scores. Second, for substance abuse $(f(1,490)=9.22(.003), p<.01 ; 4.834$ (.028) $p<.05 ; 4.10(.043), p<.05)$ in somatic scores, TOT depressive symptoms and satisfaction with life, respectively.

Third, for financial difficulties ( $f(1,490)=4.49(.034), p<.05 ; f(1,490)=15.02$ (.000), $p<.01)$ in internality and externality (chance) scores, respectively; and $(f(1,490)=73.34(.000), p<.01)$ in the satisfaction with life scores, and $(f(1,490)=$ 18.13 (.000), $p<.01 ; 13.61$ (.000), $p<.01 ; 20.11$ (.000), $p<.01 ; 17.05$ (.000), $p<.01$; 26.20 (.000), $p<.01)$ in the four CES-D subscales [depressive affect, somatic, reversed positive affect, interpersonal difficulties] and TOT depressive symptoms, respectively.

Lastly, for perception of health $(f(1,490)=12.24$ (.001), $p<.01 ; 9.19$ (.003), $p<.01$; $11.72(.001), p<.01 ; 10.62(.001), p<.01 ; 10.39(.001), p<.01)$ in the satisfaction with life, a three of CES-D subscales [depressive affect, somatic, reversed positive affect], and TOT depressive symptoms, respectively. (The experiment-wise error 
rate was controlled by performing post hoc multiple comparisons procedure and pair-wise comparisons only when the ANOVA F-test is significant')

5. According to the fourth and last research question "What are the best predictors for depressive symptoms among HU students?" A stepwise multiple regression analysis was conducted to determine the relative importance of each cognitive variable in predicting depressive symptoms (CES-D). As indicated in Table 5, the only variables entered in the analysis were satisfaction with life and externality (Chance) locus of control. The satisfaction with life (SLS) score was entered in the first step of the regression analysis, followed by externality (Chance) locus of control (MHLC). Twenty-four (0.239) percent of the variance in depression was explained by the two cognitive variables, with satisfaction with life accounting for $22 \%$, and externality (Chance) locus of

${ }^{1}$ We performed post hoc multiple comparisons procedure and pair-wise comparisons for significant (F):(Academic Achievement) Satisfaction with Life; (Substance Abuse) Satisfaction with life; TOT Depressive; (Financial Difficulties) Locus of Control (Internality), Externality [Chance], Satisfaction with life and TOT Depressive; (Perception of Health) Satisfaction with life, TOT Depressive.

By conducting Fisher's Least Significant Difference (LSD) procedure to control the comparison-wise error rate, for variables with more than two subgroups, we obtained many outcomes, for example, firstly, Post Hoc Tests (LSD) results for Grade Point Average (GPA): Perceptions of Health [PH] five subgroups (Excellent; Very Good; Good; Acceptable; Weak) indicated that for (GPA), a significant difference occurred between Excellent and Weak [GPA] levels and also between Very Good and the other [GPA] subgroups except Excellent group, with Very Good students having significantly higher Satisfaction with life (SLS) scores than students in Good, Acceptable and Weak (GPA) groups. For Perceptions of Health $[\mathrm{PH}]$ five subgroups, a significant difference in (SLS) occurred between Excellent and the other four [PH] subgroups, with Excellent group having significantly higher Satisfaction with life scores, and also between Very Good and the other three [PH] subgroups except acceptable group, with Very Good having significantly higher Satisfaction with life scores than students in Good and Weak (PH) groups. Furthermore, a significant difference in Total (Total Depressive Symptoms- TOTDS) occurred between Excellent and the other four [PH] subgroups and also between Very Good and the other three [PH] subgroups except acceptable group, with Very Good having significantly higher Satisfaction with life scores than students in Good and Weak (PH) groups.

Secondly, Pair-wise comparisons were conducted for substance abuse and for Financial Difficulties subgroups (Yes-No). The results indicated that substance abuse non-users students having significantly higher Satisfaction with life, and lower TOT Depressive symptoms scores, than students who indicated their usage of different types of drugs. Students who stated not facing Financial Difficulties reported significantly higher Satisfaction with life and higher internality scores, and lower TOT Depressive symptoms and lower externality (Chance) scores, than students who suffered from these difficulties.

2 Further preliminary statistical analyses for gender differences in depression by using (ANOVA) revealed that there was a statistically significant effect for Gender Variable $(f(l$, $490)=11,99, p<05$ ) in the total CES-D scores, in favor of females (Females, $M=23.85$, SD.11.39; males, $M=20.16$, SD.10.76). 
control style for negative events contributing for $2 \%$. Table 5 shows a summary of the regression analyses.

Table 5. Stepwise Multiple Regression of Cognitive Variables on Depressive symptoms scores ( $\mathrm{N}=492)$.

\begin{tabular}{|c|c|c|c|c|c|c|}
\hline $\begin{array}{l}\text { Predicting } \\
\text { Variables }\end{array}$ & $\mathrm{R}$ & $\mathrm{R}^{2}$ & $\begin{array}{c}\text { Adjusted } \\
R^{2}\end{array}$ & $\begin{array}{l}\text { Standardiz } \\
\text { ed } \\
\text { Coefficien } \\
\text { ts }\end{array}$ & $F$ & $P$ \\
\hline Satisfaction with life & 0.472 & 0.223 & 0.221 & -.472 & 140.63 & $\begin{array}{c}0.000 * \\
*\end{array}$ \\
\hline $\begin{array}{l}\text { Externality } \\
\text { (Chance) }\end{array}$ & 0.489 & 0.239 & 0.236 & -.455 & 76.87 & $\begin{array}{c}0.000 * \\
*\end{array}$ \\
\hline
\end{tabular}

\section{Discussion}

The purpose of this study was to establish estimates of the prevalence of depressive symptoms, and correlates of depressive symptoms, with locus of control and satisfaction with life among university students. The results showed a great ratio of depressive symptoms among HU students, almost half of collegeaged individuals had a major depression, and one-third had a moderate depression. These findings are consistent with results of some recent studies conducted in Jordan (e.g., Dellewany, 2006), and in other countries (e.g., Blanco, et al., 2008; Furr et al., 2001; Kisch et al., 2005; Weitzman, 2004) and indicate the global and internationality of this problem among those young adults. However, these results are in contrast with some research (e.g., Kanazawa, White, \& Hampson, 2007; Tsai, \& Chentsova-Dutton, 2002) that asserted the impact of culture on the prevalence of experience and presentation of depressive symptoms which have been attributed to cultural differences in the conceptualization of depression. Kanazawa and his colleagues (2007) attribute these differences to cultural variation in normative emotional expression: an individual's positive emotions and open expression may be encouraged and rewarded in Western individualistic cultures, while an individual's balance and control of emotional expression may be encouraged and rewarded in non-Western collectivistic cultures in order to maintain group harmony. Previous research suggests that at least three cultural factors may contribute to the presentation and diagnosis of depression: cultural representations of the self, mind-body relations, and emotional regulation or expression (Tsai, \& Chentsova-Dutton, 2002). 
This discrepancy may be related to the different samples used with respect to socio-demographic variables, or to the varying methods of assessment used across studies to measure depression in members of these populations (Culbertson, 1997). For instance, some researchers used the Center for Epidemiologic Studies Depression Scale while others used the Beck Depression Inventory-II to assess level of depression. This makes accurate comparisons among studies impossible and, more importantly, does not allow the literature to develop a consistent and clear understanding of depression in a particular culture group. Consequently, the discrepancy in the results of this literature deserves further attention in order to identify what factors are contributing to contradictory findings in cross-cultural studies.

Additionally, the Center for Epidemiological Studies-Depression Scale (CES-D) is used mostly for initial screening of symptoms related to depression or psychological distress (Radloff, 1977). The CES-D has also been used extensively for research purposes to investigate levels of depression among the nonpsychiatric population. However, because the CES-D does not assess the fullrange of depression symptoms (for example, it does not assess suicidality) and because it assesses the occurrence of the symptoms during the past week, the (CES-D) authors cautioned against relying on the CES-D exclusively. Accordingly, we may conclude that psychiatric individuals require more elaborate tools to generate accurate and meaningful diagnostic data (Culbertson, 1997; Radloff, 1977). We may cite what Furr and his colleagues (2001) asserted that Students' self-reports of depressive symptoms produce much higher rates than reports of clinical diagnoses of depression, with up to 53 percent of students reporting having experienced depression since beginning college.

Furthermore, this finding bears to be interpreted in light of the large number of female participants (66\%) in our study sample that may raise the ratio of depression. Gender difference in depression is among the most robust of findings in psychopathology research. Estimates are that, in adulthood, twice as many women as men are depressed (see Hyde, Mezulis, \& Abramson, 2008). Specifically, Nolen-Hoeksema $(1990,2001)$ reported also that the culture of a country is a significant determinant of female-male differences in depression. Of the studies she included in her analyses, women were diagnosed as having depressive disorders significantly more frequently than men, at a 2:1 ratio. She also found that women reported a greater number of depressive symptoms than did men. 
While gender differences in depression ${ }^{2}$ were beyond the scope of our stydy, and were not included in this study, we consider gender and depression in college students' groups an important further next research step.

Overall, the universality of this finding has prompted some (Wupperman, 2003) to suggest that college students' greater tendency toward depression may involve inherent biological or genetic cause, although little evidence for such a cause has been found. The results of this study suggest that this high prevalence rate of depression and vulnerability factors leading to depression may be more a function of social trends than they are a function of actual psychiatric disorder.

In addition, the results confirmed the relationships between the two cognitive constructs (locus of control, satisfaction with life), and depressive symptoms, among students at HU. Significant positive correlations were found among internality Locus of Control (IHLC), externality Powerful Others, and Satisfaction with Life (SLS). Additionally, the internality was negatively correlated with two subscales of depressive symptoms [reversed positive affect and interpersonal difficulties] and TOT depressive symptoms.

In contrast, externality Chance (CHLC) was correlated positively with powerful Others, the four subscales of depressive symptoms [Depressive Affect, Somatic, Reversed Positive Affect, Interpersonal Difficulties] and TOT depressive symptoms, and negatively with Satisfaction with Life (SLS). Significant negative correlations were found also among Satisfaction with Life (SLS), the four subscales of depressive symptoms depressive symptoms and TOT depressive symptoms. Additionally, significant positive correlations were found among scores in total depressive symptoms and the scores in four subscales of CES-D, and further proved high internal consistency for the scale among the study sample of college students.

These sets of correlational results are congruent with findings of some research (e.g., Afifi, 2007; Afifi et al., 2006; Benassi et al., 1988; Rapaport et al., 2005; Vandervoort, Luis, \& Hamilton, 2007). Specifically, they suggest that issues about control are related to negative affect and indicate the often-cited relationship of an external locus of control to depression. In addition, these results go in line and support Beck's (1967) cognitive theory on depression, which emphasizes the importance of adaptive beliefs in mood state. Although they are in contrast with the revised theory of learned helplessness (Abramson, Seligman, \& Teasdale, 1978), which predicts that internal expectations lead to learned 
helplessness and depression. These findings do not, however, support the view that depression is associated with different types of external locus of control, but rather suggest a unified set of locus of control beliefs underlying the four types of depressive symptoms. In addition, evidence is provided for the external validity of the Multidimensional Health Locus of Control (MHLC) Scales with respect to mental health.

Furthermore, results indicate that satisfaction with life is related to academic achievement. These results revealed that earning high-level grades influences students' perception significantly. Happier individuals appear to seek learning goals; that is, they are more interested in gaining knowledge or selfimprovement [83]. Additionally, we found that a significant relationship exists between substance abuse, depressive symptoms and dissatisfaction with life. specifically, those who depend on drugs, alcohol, and abuse tranquillizing/stimulating medications, compared to their non-dependent counterparts, seem more depressed, have more somatic complaints and are less satisfied with their lives. These results were supported by numerous studies (e.g., Blanco et al., 2008; Weitzman, 2004), and endorsed the fact that college youth who suffer from depression may be especially vulnerable to complications with alcohol. In addition, the consumption of alcohol to cope with depressive symptoms seems to increase the chances of subsequent alcohol abuse (Cooper, Russell, \& George, 1988).

Moreover, the results showed that financial difficulties place burdens on college students to the degree that affects their beliefs and interpretations of these bad stressful events they are facing, leading them to feel distressed and depressed. Those with financial problems are perceiving less control over their behavior, less belief that they control their own destiny. In contrast, they believe more that their lives are determined mainly by sources outside themselves - chance or powerful others. Consequently, they are less satisfied with their lives, and more depressed. Experiences in continuously adverse circumstances do not make life appear to be subject to control through one's own efforts. Perceived lack of control produces a feeling of helplessness and loss of hope, and diminishes an individual's will power (Lefcourt, 1991).

These results imply that depressive symptoms in young adulthood seem to be like depression in adolescence (Kinderman, \& Bentall, 1997). We found that these maladaptive symptoms are associated with such negative outcomes as academic problems, substance abuse (cigarette smoking, alcohol and drug abuse) and impaired social relationships. 
Further, the results indicate that perception of one's health may play a significant role in one's mental health. The health behavior model of the relationship between satisfaction with life, depression and physical health is sufficient to explain the relationship (Vandervoort et al., 2007).

Lastly, linear regression analysis indicated that twenty-four (0.239) percent of the variance in depressive symptoms was explained by the two cognitive constructs: satisfaction with life (SLS) and externality chance, with satisfaction with life accounting for the most of this variance $(22 \%)$, stand as the best predictors for depressive symptoms among $\mathrm{HU}$ students. These results are consistent with the cognitive model of depression, asserting the role of cognitive processing in emotion and behavior is a paramount factor in determining how an individual perceives, interprets, and assigns meaning to an event. Moreover, these results bear interpretation in light of the alienation model(Twenge et al., 2004), outlined in the introduction, where college students increasingly believed that their lives were controlled by outside forces rather than their own efforts. Apparently, the larger social forces leading to increased externality reach those young adults, leading them to be less satisfied with life and more depressed.

\section{Conclusions and Implications}

Scientifically, this study supports past research indicating the importance of student belief system as a predictor of student mental health. Also, it provides further evidence to the importance of Locus of control for effective coping behavior in the case of negative life events (i.e., low grades, financial difficulties, health problems). When faced with these events, internals tend to adopt a problem-solving strategy while the externals tend to react emotionally, for example by being sad or angry (Sarason \& Sarason, 1989, p. 441). Consequently, internals are able to leave their disappointments behind them and live happily. Externals, on the other hand, continue to carry their burdens into their future and hence are often depressed.

However, both scientifically and educationally this research fits well with the current emphasis on improving the positive elements of colleges proactively rather than retroactively trying to "fix" problems that emerge. It is important that this "reverse" (positive, proactive) view becomes part of the educational and public understanding of student success. More than that, we need to 
distinguish the important components of well-being, such as the cognitive and affective components, as they relate to the educational enterprise.

Findings of this study, specifically the high rate of depressive symptoms among college students, hold implications for depressive symptoms interventions, such as expanding psychoeducation courses to include strategies for enhancing and maintaining a sense of personal control and self-actualization. This mental health disorder in this population can be effectively treated with evidencebased psychosocial and pharmacological approaches. Specifically, Cognitive Behavior Therapy (CBT) addresses these social cognitive processes in the context of a therapeutic relationship. Prior studies have shown that cognitive behavior therapy is effective in the treatment of adolescent and young adult depression. Accordingly, establishing a skills building psycho-educational course, with a strong emphasis on behavioral skills training, in the campuses, will be effective in the treatment of college student depression (Lewinsohn, Clarke, Hops, \& Andrews, 1990; Reinecke, Ryan, \& DuBois, 1998).

Beck and Weishaar (1989) believe that in order to treat depression, clients need to treat their maladaptive interpretations and conclusions as testable hypotheses. The role of the therapist in a cognitive-behavioral intervention is to help the clients examine alternative interpretations and to produce contradictory evidence that support more adaptive patterns. According to the cognitive theory of depression proposed by Beck, "the behavioral consequences of psychopathology will depend on the content of cognitive structuring" (Beck \& Weishaar, 1989, p. 293). This relationship between therapist and client can be called collaborative empiricism because it involves a collaborative enterprise between therapist and clients in order to produce therapeutic change.

We may also suggest that involvement of students in extracurricular activities, whether sports or community service may help those at risk for depression (Hellandsjbu, Watten, Foxcroft, Ingebrigtsen, \& Relling, 2002).

\section{Limitations and Research Recommendations}

Several limitations should be taken into consideration when interpreting the results of the present study. Firstly, the use of retrospective reports of the frequency of experienced emotions instead of structured direct assessments. 
These self-evaluations include the possibility of having depression, the figure tends to be higher, and could easily be affected by memory biases.

The second potential limitation pertains in several ways to the sample used in this study. Although a simple random sampling of undergraduate students was used to allow for a large sample, as well as for a more diverse sample better representing the general population, the sample consisted mostly of female students, since the participation was voluntary and required written consent from participants (response rate was $80.6 \%$ ). A disadvantage of this strategy, in addition to the possibility of that certain significant attributes may be were under or over represented, is that this sample consisted of a large number of participants who were specifically from HU campus. This sample does not represent the whole community of college students in other Jordanian universities, which encompass the real characteristics of these young people from different Jordanian cities. Consequently, each of these factors mentioned above may limit the generalizability of results (e.g., the large number of female participants may have precluded finding significant high ratio of depression prevalence).

Therefore, a larger representative college student sample with an equal number of male and female participants from different colleges and various SES may demonstrate a larger and/or different effect size, in both the depressive symptoms, and cognitive constructs. The interrelationship of mental health problems and their clustering by group and college are important considerations for prevention and treatment.

Thirdly, our results are limited to the scales used. For example, the CES-D which was used as a measure of depressive symptoms is usually used for initial screening of symptoms related to depression or psychological distress. Therefore, it is suggested that the scale be used only as an indicator of symptoms relating to depression, not as a means to clinically diagnose depression. Using a longer but more psychometrically sound measure of the same personality constructs, such as the Depression Adjective Check Lists (DACL; Lubin, 1981; Lubin, Swearngin, \& Seaton, 1992), may have been more sensitive in detecting certain personality characteristics or more reliable in distinguishing differing personality styles.

A replication of the current study may also yield additional significant findings if conducted on a more homogeneous sample, particularly a self-described 
depressed sample. Much of the previous research conducted on depression has been done with clinically diagnosed samples.

Moreover, another possible limitation of the present study on depressive symptoms, locus of control, and satisfaction with life pertains to the statistical approach used to examine the associations between these constructs. To the extent that previous studies relied upon analysis of observed data without accounting for error of measurement, the results of such studies are at best biased estimates of the particular associations. As such, a more sophisticated data analytic approach is considered helpful in elucidating the relationships among these constructs.

Furthermore, the last limitation relates to the demographic predictors that were not included in this study, and accordingly, prevent discovering some important data. This supports further analyses and replication with these kinds of predictors. However, it was not the intention of our study to report how gender, socioeconomic status, students' faculty, year, or interaction between these factors affected depression differently among those students. Determining the prevalence of depression in college students and their correlates with locus of control and satisfaction with life was the purpose of this research.

Clearly, replication of this study's results on different samples and with different scales is essential. Further research will be required to determine the effect of gender on depression, locus of control and satisfaction with life, whether the lower mean score of externality locus of control is the result of lower reporting of depression on this instrument (CES-D), the actual experiencing of less depression, or a social desirability effect. Further studies might also evaluate whether gender or socioeconomic status has played a role in these results. Biafora (1995) found that by controlling for socioeconomic status, differences in depression scores among students from different races could be eliminated. Additionally, investigations should attempt to ascertain what places college students at a lower risk of developing depression than non-college students.

Finally, despite these limitations, the present study has successfully provided some useful information for planning and designing effective counseling interventions. Colleges and universities rely on this kind of research to support and train faculty and staff to identify students who are at risk for depression, foster peer support programs and ensure that mental health and counseling services are available (Brener, Hassan, \& Barrios, 1999). Early treatment could reduce the persistence of this disorder and its associated functional 
impairment, loss of productivity and increased health care costs. As these young people represent our nation's future, urgent action is needed to increase detection and treatment of mental health disorders among college students.

\section{References}

Abramson, L. Y., Metalsky, F. I., \& Alloy, L. B. (1989). Hopelessness depression: A theory based subtype of depression. Psychological Review, 96(2), 358-372.

Abramson, L. Y., Seligman, M. E. P., \& Teasdale, J. D. (1978). Learned helplessness in humans: critique and reformulation. Journal of Abnormal Psychology, 87, 49- 74.

Afifi, M. (2007). Health locus of control and depressive symptoms among adolescents in Alexandria, Egypt. Eastern Mediterranean Health Journal, 13 (5), 1043-1052.

Afifi, M., Al Riyami, A., Morsi, M., \& Al Kharusil, H. (2006). Depressive symptoms among high school adolescents in Oman. Eastern Mediterranean Health Journal, 12 (Supplement n.2), s126-S137.

Al-Khulaidi, R. A. (2004). Depression in university students: gender, personality type and stress as correlates. Unpublished Master Thesis, University of Jordan, Amman, Jordan.

Banks, L. M., \& Goggin, W. C. (1983). The relationship of locus of control and attribution to depression. (Report No. CG-017). Paper presented at the annual Meeting of the Southeastern Psychological Association (29th, Atlanta, GA, March 23-26, 1983). (ERIC Document No. ED236461).

Beck, A. T. (1967). Depression: clinical, experimental, and theoretical aspects. New York: Hoeber Medical Division, Harper \& Row.

Beck, A. T., \& Weishaar, M. E. (1989). Cognitive Therapy. In D. Corsini \& D. Wedding (eds.), Current Psychotherapies (pp. 285-317), IL: Peacock Club.

Benassi, V. A., Sweeney, P. D., \& Dufour, C. L. (1988). Is there a relation between locus of control orientation and depression? Journal of Abnormal Psychology, 97, 357-367. 
Biafora, F. (1995). Cross-cultural perspective on illness and wellness: Implications for depression. Conference on Multicultural perspectives on mental illness (1994, St. John's University, New York). Journal of Social Distress \& the Homeless, 4 (2), 105-129.

Blanco, C., Okuda, M., Wright, C., Hasin, D.S., Grant, B. F., Liu, S-M., \& Olfson, M. (2008). Mental health of college students and their non-college-attending peers: Results from the national epidemiologic study on alcohol and related conditions. Archives of General Psychiatry, 65 (12), 1429-1437.

Brener, N.D., Hassan, S.S., \& Barrios, L.C. (1999). Suicidal Ideation Among College Students in the United States. Journal of Consulting Psychology, 67, 1004-1008.

Brown, J. D., \& Siegel, J. M. (1988). Attribution for negative life events and depression: The role of perceived control. Journal of Personality and Social Psychology, 54, 316-322.

Burger, J. M. (1984). Desire for control, locus of control, and proneness to depression. Journal of Personality, 52 (1), 71-89.

Chubb, N. H., \& Fertman, C.I. (1997). Adolescent self-esteem and locus of control: a longitudinal study of gender and age differences. Adolescence, 32, 113-130.

Cooper, L., M. Russell, \& George, W.H. (1988). Coping, expectancies, and alcohol abuse: A test of social learning formulations. Journal of Abnormal Psychology, 97, 218-230.

Crowne, D. P., \& Liverant, S. (1963). Conformity under varying conditions of personal commitment. The Journal of Abnormal and Social Psychology, 66 (6), 547-555.

Culbertson, F. (1997). Depression and gender. An international review. American Psychologist, 52(1), 25-31.

Dellewany, T. (2006, Nov 23). The growing phenomenon of suicide in Jordan! Psychological depression is the main reason. Retrieved May, 18, 2008 from http://www.asyeh.com/asyeh_world.php?action=showpost\&id=1069

Diener, E., Emmons, R., Larsen, J., \& Griffin, S. (1985). The satisfaction with life scale. Journal of Personality Assessment, 49 (1), 71-75. 
Diener, E., Oishi, S., \& Lucas, R. E. (2003). Personality, culture, and subjective wellbeing: Emotional and cognitive evaluations of life. Annual Review of Psychology, 54, 403-425.

Fukuyama, F. (1999). The great disruption: Human nature and the reconstitution of social order. New York: Free Press.

Furr, S. R., Westefeld, J. S., McConnell, G. N., \& Jenkins, J. M. (2001). Suicide and depression among college students: A decade later. Professional Psychology: Research and Practice, 32 (1), 97-100.

Haley, G.M., Fine, S., Marriage, K., Moretti, M.M., \& Freeman, R.J. (1985). Cognitive bias and depression in psychiatrically disturbed children and adolescents. Journal of Consulting and Clinical Psychology, 53, 535-537.

Hamid, H., Abu-Hijleh, H. H., Sharif, N.S., Raqab, S. L., Mas'ad, Z. M., \& Abbas, D. A. (2004). A primary care study of the correlates of depressive symptoms among Jordanian women. Transcultural Psychiatry, 41 , 487-96.

Hellandsjbu, E. T., Watten, R. G., Foxcroft, D. R., Ingebrigtsen, J. E., \& Relling, G. (2002). Teenage alcohol and intoxication debut: The impact of family socialization factors, living area and participation in organized sports. Alcohol and Alcoholism, 37 (1), 74-80.

Hong, S., \& Giannakopoulos, E. (1994). The relationship of satisfaction with life to personality characteristics. Journal of Psychology, 128, 547- 558.

Hyde, J. S., Mezulis, A. H., \& Abramson, L. Y. (2008). The ABCs of depression: Integrating affective, biological, and cognitive models to explain the emergence of the gender difference in depression. Psychological Review, 115, 291-313. doi: 10.1037/0033-295X.115.2.291

Kanazawa, A., White, P. M., \& Hampson, S. E. (2007). Ethnic variation in depressive symptoms in a Hawaiian community sample. Cultural Diversity and Ethnic Minority Psychology, 13(1), 35-44.

Kelman, H. C., \& Lawrence, L. H. (1972). Assignment of responsibility in the case of Lt. Calley. Journal of Social Issues, 28, 177-212.

Kessler, R., Berglund, P., Demler, O., Jin, R., Merikangas, K., \& Walters, E. (2005). Lifetime prevalence and age-of-onset distributions of DSM-IV disorders in the 
National Comorbidity Survey Replication. Archives of General Psychiatry, 62, 593602.

Kinderman, P., \& Bentall, R. P. (1997). Causal Attributions in Paranoia and Depression Internal, Personal, and Situational Attributions for Negative Events. Journal of Abnormal Psychology, 106 (2), 341-345.

Kisch, J., Leino, V., \& Silverman, M. (2005). Aspects of suicidal behavior, depression, and treatment in college students: Results from the spring 2000 National College Health Assessment Survey. Suicide and Life-Threatening Behavior, 35, 3-13.

Klonowicz, T. (2001). Discontented people: Reactivity and locus of control as determinants of subjective well-being. European Journal of Psychology, 15, 29-47.

Lefcourt, H. M. (1991). Locus of control. In J. P. Robinson, P. R. Shaver, \& L. S. Wrightsman (Eds.), Measures of personality and social psychological attitudes (pp. 413-499), New York: Academic Press.

Levenson, H. (1973). Multidimensional locus of Levenson's measures of 'powerful others' LOC. control in psychiatric patients. Journal of Consulting and Clinical Psychology, 41 , 397-404.

Lewinsohn, P., Clarke, G., Hops, H., \& Andrews, J. (1990). Cognitive-behavioral group treatment of depression in adolescents. Behavior Therapy, 21 , 385-401.

Lubin, B. (1981). Depression Adjective Check Lists: Manual (2 ${ }^{\text {nd }} . e d$.).San Diego, CA: Educational and Industrial Testing Service.

Lubin, B., Swearngin, S., \& Seaton, K. (1992). Research with the Depression Adjective Check Lists, 1965-1991. Odessa, FL: Psychological Assessment Resources.

Marano, H. E. (2002). Mending minds: Lessons from college. Retrieved October 22, 2008 from http://www.psychologytoday.com.

McCauley, E., Mitchell, J., Burke, E., \& Moss, S. (1988). Cognitive attributes of depression in children and adolescents. Journal of Consulting and Clinical Psychology, 56, 903-908.

Murphy, G. \& Wetzel, R. (1990). The Lifetime Risk of Suicide in Alcoholism. Archives of General Psychiatry, 47, 383-390. 
National Center on Addiction and Substance Abuse (NCASA), Columbia University. (2003). Depression, Substance Abuse and College Student Engagement: A Review of the Literature. Report to The Charles Engelhard Foundation and the Bringing Theory to Practice Planning Group. Retrieved August 12, 2008 from http://www.bringingtheorytopractice.org/pdfs/LitReviewDec03.pdf

Nolen-Hoeksema, S. (1990). Sex differences in depression. Stanford, CA: Stanford University Press.

Nolen-Hoeksema, S. (2001). Gender differences in depression. Current Directions in Psychological Science, 10 (5), 173-176.

Nolen-Hoeksema, S., Larson, J., \& Grayson, C. (1999). Explaining the gender difference in depressive symptoms. Journal of Personality and Social Psychology, 77, 1061-1072.

Norman, P., \& Bennett, P. (1996). Health Locus of Control. In M. Conner \& P. Norman (Eds.), Predicting Health Behavior (pp. 26-94), Philadelphia: Open University Press.

Nunn, G. D. (1995). Effects of a learning styles and strategies intervention upon atrisk middle school students' achievement and locus of control. Journal of Instructional Psychology, 21, 421-433.

Pavot, W., Diener, E., Colvin, C., \& Sandvik, E. (1991). Further validation of the Satisfaction with Life Scale: Evidence for the cross-method convergence of wellbeing measures. J Personality Assessment, 57(1), 149-161.

Pelkonen, M., Marttunen, M., \& Aro, H. (2003). Risk for depression: A 6-year follow-up of Finnish adolescents. Journal of Affective Disorders, 77, 41-51.

Petersen, A. C., Compas, B. E., Brooks-Gunn, J., Stenmmler, M., Ey, S., \& Grant, K. E. (1993). Depression in adolescence. American Psychologist, 48, 155-168.

Pharr, S. J., Putnam, R. D., \& Dalton, R. J. (2000). A quarter-century of declining confidence. Journal of Democracy, 11, 5-25.

Radloff, L. S. (1977). The Center for Epidemiologic Studies Depression Scale (CES-D) scale: A self-report depression scale for research in general population. Applied Psychological Measurement, 1, 385 -401. 
Rapaport, M. H., Clary, C., Fayyad, R., \&Endicott, J. (2005). Quality-of-life impairment in depressive and anxiety disorders. American Journal of Psychiatry, $162,1171-1178$.

Reinecke, M., Ryan, N., \& DuBois, D. (1998). Cognitive-behavioral therapy of depression and depressive symptoms during adolescence: A review and metaanalysis. Journal of the American Academy of Child and Adolescent Psychiatry, 37 , 26-34.

Rotter, J. B. (1966). Generalized expectancies for internal versus external control of reinforcement. Psychological Monographs: General and Applied, 80 (1), 1-26.

Sarason, L. \& Sarason, B. R. (1989). Abnormal Psychology (6 th ed.). New York: Prentice-Hall.

Simpson, P.L., Schumaker, J.F., Dorahy, M.J., \& Shrestha, S.N. (1996). Depression and life satisfaction in Nepal and Australia. Journal of Social Psychology, 136, 783-790.

Sloan, T. (1996). Damaged life: The crisis of the modern psyche. New York: Routledge.

Spector, P. E., Shima, O. L., Siv, J. B., Stora, M., Teichmann, T., Theorell, P., et al. (2001). Do National Levels of Individualism and Internal Locus of Control Relate to Well-being: An Ecological Level International Study. Journal of Organizational Behavior, 22, 815-832.

Sunders, S., \& Roy, C. (2000) The relationship between depression, satisfaction with life, and social interest. South Pacific Journal of Psychology, 11 (1), 9-15.

Tones, K. (1997). Health education, behaviour change, and the public health. In R. Detels, W. Holland, J. McEwen, \& G, Omenn (eds.), Methods of public health (3rd, ed.), Volume, 2 (pp.791-814), New York: Oxford University Press.

Tsai, J.L., \& Chentsova-Dutton, Y. (2002). Understanding depression across cultures. In I.H. Gotlib \& C. L. Hammen (eds.), Handbook of Depression (pp. 467-491), New York: Guilford Press.

Twenge, J. M., Zhang, L., \& Im, C. (2004). It's Beyond My Control: A Cross-Temporal Meta-Analysis of Increasing Externality in Locus of Control, 1960-2002. Personality and Social Psychology Review, 8 (3), 308-319. 
Vandervoort, D. J., Luis, P. K., \& Hamilton, S. E. (2007). Some correlates of health locus of control among multicultural individuals. Current Psychology, 16 (2), 167-178.

Wallston, K. A., Wallston, B. S., \& DeVellis, R. (1978). Development of the multidimensional health locus of control (MHLC) scales. Health Education Monographs, 6, 160-170.

Wardle, J., Steptoe, A., Gulis, G., Sartory, G., Sek, H., \& et al. (2004). Depression, perceived control, and life satisfaction in university students from central-eastern and western Europe. International Journal of Behavioral Medicine, 11 (1), 27-36.

Weisz, J. R., Sweeney, L., \& Carr, T. (1993). Control-related beliefs and self-reported depressive symptoms in late childhood. Journal of Abnormal Psychology, 102, 411 418.

Weitzman, E. R (2004). Poor mental health, depression, and associations with alcohol consumption, harm, and abuse in a National Sample of Young Adults in College. The Journal of Nervous and Mental Disease, 192 (4), 269-277.

Wupperman, P. (2003). Differences in depression as a function of gender roles and rumination. Unpublished Master Thesis. University of North Texas. Retrieved January 11, 2009 from www.library.unt.edu/theses/open/20033/wupperman_peggilee/thesis.pdf

About the authors:

Jehad Alaedein Zawawi, Ph.D. Counseling Psychology, is Assistant professor, Department of Educational Psychology at the Faculty of Educational Sciences, Hashemite UniversityJordan. Her research interests include prevention group counseling, gender-based personality differences, and mental \& physical health counseling rehabilitation. She is also a teacher of Theories of Counseling, Group and Family Counseling for Undergraduate and Graduate Students.

E-mail: Jehadala@hu.edu.jo

Shaher H. Hamaideh, Ph.D. Psychiatric-Mental Health Nursing -Adults, is Assistant Professor, Department of Community \& Mental Health Nursing, at the Faculty of Nursing, Hashemite University-Jordan. His research interests focus on Mental Illness Stress, Coping Addiction and Substance abuse and Women's Mental Health Stress. He is also a teacher of Mental Health Nursing, Education and Group Counseling for Undergraduate and Graduate nursing Students.

E-mail: shaher29@hu.edu.jo 